\title{
Meal pattern and BMI in 9-11-year-old children in Finland
}

\author{
Reetta Lehto ${ }^{1, *}$, Carola Ray ${ }^{1,2}$, Marjaana Lahti-Koski ${ }^{3}$ and Eva Roos ${ }^{1,2}$ \\ ${ }^{1}$ Folkhälsan Research Center, Paasikivenkatu 4, 00250 Helsinki, Finland: ${ }^{2}$ Department of Public Health, \\ Hielt Institute, University of Helsinki, Finland: ${ }^{3}$ Finnish Heart Association, Helsinki, Finland
}

Submitted 16 March 2010: Accepted 16 September 2010: First published online 6 December 2010

\begin{abstract}
Objective: In many studies it has been shown that breakfast is associated with normal weight in children and adolescents. Other meals, family meals and a regular meal pattern have been less studied. Therefore, the aim of the present study was to examine whether a regular meal pattern, or breakfast, lunch or dinner as separate regular meals, is associated with the BMI of children.

Design: A cross-sectional study conducted within the Helsinki region during 2006. Study participants were measured and weighed by research staff. Children filled in a study questionnaire on their health behaviour, including the frequency of consuming meals. A regular meal was defined as one usually eaten on every school day. A regular meal pattern was defined as one consisting of a usual consumption of breakfast, school lunch and dinner on every school day. Covariance analysis was used as the statistical analysis method.

Setting: Capital region, Finland, 2006.

Subjects: A total of 604 schoolchildren (312 girls) aged 9-11 years.

Results: Irregular breakfast and an irregular meal pattern were associated with higher BMI. Regularity of school lunch, dinner or family dinner was not associated with BMI.

Conclusions: A regular breakfast and meal pattern was associated with lower BMI in children, although breakfast was the only single meal associated with BMI. We conclude that, although the association between breakfast and weight status in children is fairly consistent, the role of other meals is less convincing.
\end{abstract}

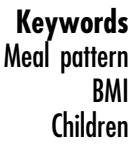

The prevalence of overweight has increased considerably among children during the last decades and is now at approximately $15-30 \%$ in most Western countries ${ }^{(1)}$. Although chronic energy surplus is the ultimate reason for developing overweight, many factors, most importantly those related to diet and physical activity, contribute to this imbalance. Missing meals and/or eating snacks is one factor that could influence weight status, because consuming breakfast or having a regular meal pattern has been found to be associated with an increased consumption of fruit and vegetables and lowering of soft drink consumption, and having a diet with a higher nutrient density, e.g. fibre ${ }^{(2-6)}$. The association between consumption of meals and weight status can also be due to factors unrelated to food. For example, regular consumption of breakfast can be an indicator of an already healthy lifestyle ${ }^{(7)}$. This could also be the case with other meals.

Having a regular breakfast has been shown to be associated with normal weight in children and adolescents in cross-sectional $^{(4,8,9)}$ and prospective studies alike ${ }^{(10-15)}$. Only few studies have examined the relationship of meals other than breakfast to weight status. So far, no clear association has been found between eating a school lunch and weight status ${ }^{(16-18)}$, although some studies have found a positive association ${ }^{(19,20)}$. Most of these studies have been conducted in countries where only a section of the students have a free school lunch available to them ${ }^{(21)}$; therefore, the situation might be different in Finland, as a cooked school lunch is provided free of charge to everyone. Most cross-sectional studies have shown that consuming fewer family dinners has an association with overweight or higher $\mathrm{BMI}^{(19,22-25)}$, but results from prospective studies are less clear ${ }^{(22,23)}$. Dinner irregularity and its association with overweight has not, to our knowledge, been studied previously. There have been a few studies on specific meal patterns and weight status in schoolchildren. A couple of studies have found that there is an association between consuming three main meals a day and a lower BMI ${ }^{(26,27)}$, but inconclusive results also exist ${ }^{(27,28)}$.

The aim of the present study was to examine whether regular breakfast, school lunch, dinner, family dinner or an overall regular meal pattern is associated with the BMI of schoolchildren in Finland. In the present study, a 
regular meal pattern refers to consuming breakfast, lunch and dinner daily during the school week.

\section{Materials and methods}

The present study was performed as a part of a project called Hälsoverkstaden (Health workshop), which studies the health behaviour of 9-11-year-old children in Finland. The study material is cross-sectional and was collected from Swedish-speaking elementary schools in the capital region in 2006. Headmasters in all the Swedish-speaking schools with more than fifty pupils in the capital region ( $n$ 44) were asked whether their school would take part in the project; twenty-seven agreed to participate. Those schools that declined were not different in terms of socioeconomic status (SES) from those that chose to participate. The study was granted the approval of the ethics committee of the University of Helsinki's public health department.

In the spring of 2006, 1054 children and their parents were contacted, of whom 677 gave their informed consent for participation in the study. Data were collected during two visits to the schools. The response rate was $60 \%$. During the first visit in the spring, 630 children were measured and weighed by research staff. The forty-seven children who did not take part were either absent during the measurements or declined to be measured. During the fall, 604 of those children who had been measured completed a questionnaire on their health behaviour. These 604 children form the final sample of our study. The twenty-six children who did not complete the questionnaire in the fall had been absent on that particular school day. The questionnaire was completed in a classroom setting with a member of the research staff always present.

\section{Antbropometrics}

All the children were weighed before lunchtime using the same study scale to the nearest $0 \cdot 1 \mathrm{~kg}$ wearing only underwear and a T-shirt. The children's height was measured to the nearest $0.5 \mathrm{~cm}$ using the same study measure. BMI was calculated as weight in kilograms divided by the square of height in metres $\left(\mathrm{kg} / \mathrm{m}^{2}\right)$.

\section{Meal pattern}

The children were asked on how many days during a school week they usually consumed breakfast. The alternative answer choices ranged from zero to five. Similar questions were asked about school lunch and dinner. The same questions have been used in the WHO Health Behavior of School-aged Children (HBSC) study questionnaire $^{(29)}$. We defined any meal normally eaten on $5 \mathrm{~d}$ during the school week as a regular meal and all other alternatives as irregular meals. We defined a regular meal pattern as one consisting of a usual consumption of breakfast, school lunch and dinner during all $5 \mathrm{~d}$ during the school week. In addition, a question on the family's dining habits was asked. The child was classified as eating a family dinner if he/she answered that 'a cooked meal with the family usually eating together' best describes his/her family's dinner habits.

\section{Confounders}

The questionnaire included questions on children's health behaviour and family determinants, which were mostly from the HBSC study questionnaire ${ }^{(29)}$. Since diet, physical activity, screen time, sleep duration and the family's SES have been associated with both BMI and meal pattern in other studies ${ }^{(1,7)}$, questions indicating these factors were treated as possible confounders in the analyses. In this way, a more independent association between meals and BMI can be revealed.

We asked the children about the amount of time that they spend on free-time physical activity with six alternative answers ranging from 'not at all' to ' $\geq 7 \mathrm{~h} /$ week'. Sleep duration was calculated on the basis of questions about the time the children went to bed and woke up during the school week. Total television (TV) viewing and computer screen time per day during the school week were calculated through two questions, one on TV, video and digital video disc viewing time and the other on time spent using a computer or playing with game consoles. The seven alternative answers ranged from 'not at all' to 'approximately $\geq 5 \mathrm{~h} / \mathrm{d}$ '.

A sixteen-item FFQ was used to identify dietary patterns by principal component analysis, which has been described in detail previously ${ }^{(30)}$. Two factors were identified, the first of which included pizza, hamburgers, hot dogs and meat pastries, potato chips and popcorn, cookies, ice cream, sweets, chocolate, cola and other soft drinks. This factor was named the energy-dense food index. The other factor, which we called the nutrientdense food index, consisted of fresh vegetables, cooked vegetables, fruit, berries and rye bread.

The SES of the families could not be directly taken into account in the present study because the children were too young to answer questions related to it. Instead, we used family structure and parents' employment status as substitutes. On the basis of answers about family structure, participants were divided into those who lived with both parents and those who had other family structures, and on the basis of questions on mother's and father's employment, both mothers and fathers were divided into those who worked full time and those who did not.

\section{Statistical methods}

The gender differences in the prevalence of overweight, regularity of meals and other variables were tested with the $t$ test and the $\chi^{2}$ test. Associations between regularity of meals and BMI were tested with covariance analysis. The Statistical Package for the Social Sciences statistical 
Table 1 Descriptive data on the study sample: schoolchildren ( $n$ 604) aged 9-11 years, capital region, Finland, 2006

\begin{tabular}{|c|c|c|c|c|c|c|}
\hline Characteristics & Girls' average & $95 \% \mathrm{Cl}$ & Boys' average & $95 \% \mathrm{Cl}$ & Total average & $95 \% \mathrm{Cl}$ \\
\hline$n$ & 312 & & 292 & & 604 & \\
\hline Age (years)* & $9 \cdot 6$ & $9 \cdot 6,9 \cdot 7$ & $9 \cdot 7$ & $9 \cdot 6,9 \cdot 7$ & $9 \cdot 6$ & $9 \cdot 6,9 \cdot 7$ \\
\hline Height $(\mathrm{cm})$ & $143 \cdot 6$ & $142 \cdot 7,144 \cdot 5$ & $144 \cdot 3$ & $143 \cdot 6,145 \cdot 0$ & $144 \cdot 0$ & $143.4,144.5$ \\
\hline Weight (kg) & $36 \cdot 4$ & $35 \cdot 5,37 \cdot 2$ & $36 \cdot 8$ & $35 \cdot 9,37 \cdot 6$ & $36 \cdot 6$ & $36 \cdot 0,37 \cdot 2$ \\
\hline \multirow[t]{2}{*}{ BMI $\left(\mathrm{kg} / \mathrm{m}^{2}\right)$} & $17 \cdot 5$ & $17 \cdot 2,17 \cdot 8$ & $17 \cdot 5$ & $17 \cdot 3,17 \cdot 8$ & $17 \cdot 5$ & $17 \cdot 3,17 \cdot 7$ \\
\hline & \multicolumn{2}{|c|}{ Prevalence (\%) } & \multicolumn{2}{|c|}{ Prevalence (\%) } & \multicolumn{2}{|c|}{ Prevalence (\%) } \\
\hline Overweight/obeset & \multicolumn{2}{|c|}{17} & \multicolumn{2}{|c|}{17} & \multicolumn{2}{|c|}{17} \\
\hline Obeset & \multicolumn{2}{|c|}{3} & \multicolumn{2}{|c|}{1} & \multicolumn{2}{|c|}{2} \\
\hline Regular breakfast & \multicolumn{2}{|c|}{88} & \multicolumn{2}{|c|}{85} & \multicolumn{2}{|c|}{87} \\
\hline Regular school lunch & \multicolumn{2}{|c|}{91} & \multicolumn{2}{|c|}{87} & \multicolumn{2}{|c|}{89} \\
\hline Regular dinnerł & \multicolumn{2}{|c|}{90} & \multicolumn{2}{|c|}{84} & \multicolumn{2}{|c|}{87} \\
\hline Regular meal pattern & \multicolumn{2}{|c|}{72} & \multicolumn{2}{|c|}{67} & \multicolumn{2}{|c|}{70} \\
\hline Family dinner & \multicolumn{2}{|c|}{80} & \multicolumn{2}{|c|}{78} & \multicolumn{2}{|c|}{79} \\
\hline Screen time (h/school day) $\ddagger$ & & & & & & \\
\hline$\leq 1 \cdot 0$ & \multicolumn{2}{|c|}{36} & \multicolumn{2}{|c|}{24} & \multicolumn{2}{|c|}{30} \\
\hline $1 \cdot 5-2 \cdot 5$ & \multicolumn{2}{|c|}{37} & \multicolumn{2}{|c|}{38} & & \\
\hline$\geq 3 \cdot 0$ & & & & & & \\
\hline Sleep duration (h/school day) & & & & & & \\
\hline$\leq 9 \cdot 0$ & & & & & & \\
\hline $9 \cdot 5-10 \cdot 0$ & & & & & & \\
\hline$\geq 10.5$ & & & & & & \\
\hline Physical activity (h/week) $\ddagger$ & & & & & & \\
\hline At least 7 & & & & & & \\
\hline $4-6$ & & & & & & \\
\hline$<4$ & & & & & & \\
\hline Family structure & & & & & & \\
\hline Child lives with both parents & & & & & & \\
\hline Parents' employment status & & & & & & \\
\hline Mother works full time & & & & & & \\
\hline Father works full time & & & & & & \\
\hline Both parents work full time & & & & & & \\
\hline
\end{tabular}

*During anthropometric measurements.

tAccording to Cole et al. ${ }^{(31)}$.

$\ddagger$ Significant difference between boys and girls $\left(\chi^{2}\right.$ test, $\left.P<0 \cdot 05\right)$.

software package version $17 \cdot 0$ for Windows (SPSS Inc., Chicago, IL, USA) was used as the statistical program.

Three different models were used. The first model was adjusted only for age and gender and the second for age, gender and children's health behaviours, such as freetime physical activity, sleep duration, screen time and the two food indices. In the third model, family structure and parents' employment status were added to model 2.

\section{Results}

Anthropometrics, the regularity of meals and other health behaviours in children are described in Table 1. Eating a regular dinner was more prevalent among girls than among boys. Gender differences were also found to relate to screen time and physical activity, with boys reporting that they spend more time engaging in these activities. Of those children who ate breakfast regularly, $90 \%$ also ate school lunch regularly and $89 \%$ also ate a regular dinner. The proportion of children who ate all meals regularly is shown in Table 1.

Irregular consumption of breakfast was associated with a higher BMI in all the statistical models (Table 2). The regularity of school lunch, dinner or family dinner was not associated with the children's BMI. Irregular meal patterns were associated with a higher BMI in all statistical models.

\section{Discussion}

In the present cross-sectional study of 9-11-year-old children in Finland, irregular consumption of breakfast and irregular meal patterns during a school week were associated with higher BMI. Either eating a school lunch or dinner regularly or usually eating a dinner with the family was not associated with BMI.

The present study confirms previous results from crosssectional studies on the associations of breakfast consumption with weight status ${ }^{(3,4,8,9)}$. As in the present study, previous results on school lunch consumption relative to weight status have mostly shown no relationship ${ }^{(16-20)}$. Previous studies that focus only on dinner are lacking. Studies on family dinner and weight status have yielded inconsistent results. Contrary to our results, most ${ }^{(19,22,23,25)}$ but not all ${ }^{(24)}$ cross-sectional studies have found that fewer family dinners are related to higher BMI. In follow-up studies, the association between family dinner and BMI has 
Table 2 Associations between regularity of breakfast, school lunch, dinner, family dinner and meal pattern and BMI (covariance analysis): schoolchildren ( $n$ 604) aged 9-11 years, capital region, Finland, 2006

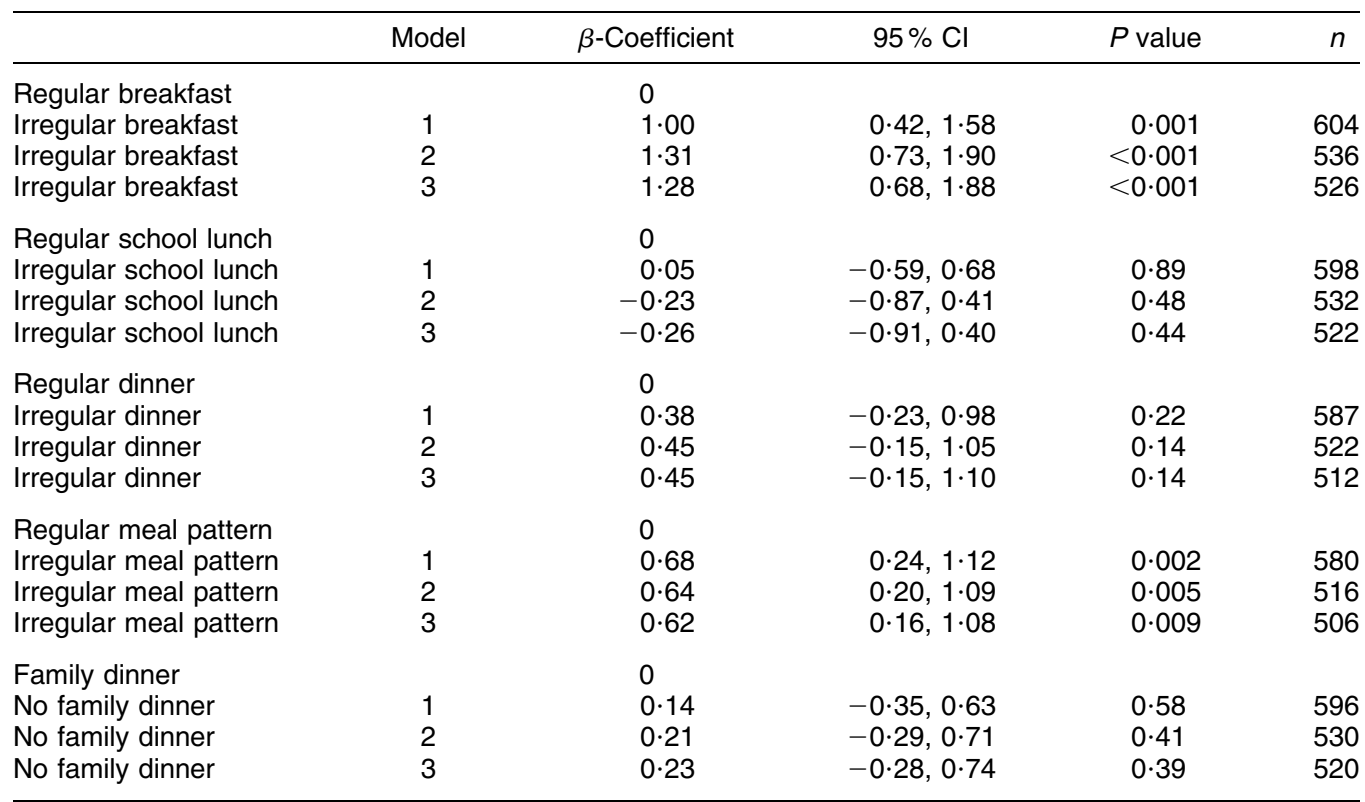

Models adjusted as follows: Model 1 for age and sex; Model 2 for model 1 items + sleep duration on school week, physical activity, screen time, energy-dense food index and nutrient-dense food index; Model 3 for model 2 items + mother's and father's employment and family structure.

not been found ${ }^{(23)}$ or has only been found in connection with one ethnic subgroup of American adolescents ${ }^{(22)}$.

In concordance with our results, Franko et al. ${ }^{(26)}$ reported that consuming at least three meals per day was associated with a lower BMI in American girls. In a Brazilian study on low-SES adolescents, having breakfast, lunch and dinner on a daily or almost daily basis was associated with a lower BMI in boys, but not in girls ${ }^{(27)}$. Contrary to our findings, a previous Finnish study on 13- and 15-year-old adolescents found that having a regular meal pattern during a school week was not associated with being overweight ${ }^{(28)}$.

In the present study, the association between meal patterns and BMI was mostly due to the regularity of breakfast, since neither the regularity of school lunch nor of dinner alone was found to be associated with BMI. It may be that breakfast, but not other meals, is an indicator of a healthier diet or otherwise healthy lifestyle that promotes healthy BMI. Studies have shown that missing out on breakfast is associated with less healthy behaviours such as lower levels of physical activity, higher levels of TV viewing, plus smoking and the consumption of alcohol in adolescents ${ }^{(3,7,15)}$. Nevertheless, our results were uninfluenced by adjusting for other health behaviours. Regular breakfast consumption has consistently been linked with healthier diets ${ }^{(2,4,9,15,32)}$. In contrast, those who tend to miss out on breakfast report higher energy consumption from snacks than those who consume breakfast regularly ${ }^{(2,9)}$. However, in the present study, children's food choices were taken into account to some extent but had no effect on the results.
The association between breakfast regularity and BMI could be explained by energy intake, but in almost all studies children and adolescents who have reported consuming breakfast regularly have also reported higher energy intake compared with those who consume breakfast irregularly ${ }^{(4,9,15,32)}$. This odd finding could be due to the under-reporting by the irregular breakfast takers. Overweight adolescents are known to under-report their food intake more than normal weight adolescents ${ }^{(33,34)}$. It might also be explained by higher physical activity among the regular consumers of breakfast ${ }^{(7)}$.

In recent studies, shorter sleep duration has been associated with being overweight in children ${ }^{(35)}$. However, there are little data on the possible associations between sleep duration and breakfast consumption. As has been shown in a few studies ${ }^{(36,37)}$ it is possible that children who sleep less also tend to miss out on breakfast. Thus, it is also possible that sleep duration explains part of the association between breakfast consumption and BMI.

The possibility of reverse causality must be taken into account within a cross-sectional research setting. Children with a high BMI might have stopped eating breakfast regularly after their weight gain in an attempt to lose weight, since this has been reported to be a popular dieting method among 11-16-year-old adolescents, especially with girls ${ }^{(38,39)}$. No data are available relating this to younger children.

One of the strengths of the present study is that the children were measured and weighed specifically for the present study by the research staff. Self-reported or parent-reported weights and heights would have been prone to errors and 
under-reporting ${ }^{(40,41)}$. Another strength of the study is that many other factors that are possibly linked to childhood overweight were studied, allowing the many confounding factors to be taken into account when adjusting the results.

A weakness of the present study is that the sample was selective and quite homogeneous, as it represented a language minority in the capital region of Finland. The parents of the study population had a better-than-average level of education. However, the results of other studies are similar enough to confirm our results. As the study sample was quite small, the results were not shown separately for boys and girls.

There is a question about the ability of children of this age to accurately report their behaviour. However, it has been found that children of this age are able to report quite well, at least on their food habits ${ }^{(42,43)}$. There is also a previous study showing that slightly older children are able to report their sleep duration ${ }^{(44)}$. Furthermore, the same questions on health behaviour have also been used in the HBSC study of 11-15-year-olds ${ }^{(29)}$.

In the present study, we have examined the regularity of breakfast, school lunch, dinner and family dinner independently to see what association they may have with children's BMI. We also examined if a regular meal pattern, defined as breakfast, school lunch and dinner, was associated with children's BMI. The present study adds to our knowledge about the association of regular mealtimes and meal patterns with BMI. We conclude that, although the association between breakfast consumption and BMI in children is fairly consistent, the role of other meals is unclear. Further research into the associations of other meals using a larger and representative sample would be needed. Until such data are available, the assumption must be that breakfast is by far the most important meal of the day, from the point of view of weight.

\section{Acknowledgements}

The present study was financially supported by the Juho Vainio Foundation, Päivikki; the Sakari Sohlberg Foundation, Signe; the Ane Gyllenberg Foundation; and the Medicinska understödsförening Liv och Hälsa. None of the authors had any conflict of interest. E.R. and C.R. contributed to the study design and planning and collected the study data. R.L. conducted the statistical analyses. All authors, including M.L.-K., contributed to the interpretation of the results and preparation of the manuscript. The authors thank all the schools studied, children and their parents for their participation in the study.

\section{References}

1. Lobstein T, Baur L, Uauy R et al. (2004) Obesity in children and young people: a crisis in public health. Obes Rev $\mathbf{5}$, Suppl. 1, S4-S104.
2. Sjoberg A, Hallberg L, Hoglund D et al. (2003) Meal pattern, food choice, nutrient intake and lifestyle factors in The Goteborg Adolescence Study. Eur J Clin Nutr 57, 1569-1578.

3. Keski-Rahkonen A, Kaprio J, Rissanen A et al. (2003) Breakfast skipping and health-compromising behaviors in adolescents and adults. Eur J Clin Nutr 57, 842-853.

4. Rampersaud GC, Pereira MA, Girard BL et al. (2005) Breakfast habits, nutritional status, body weight, and academic performance in children and adolescents. $J$ Am Diet Assoc 105, 743-760.

5. Siega-Riz AM, Carson T \& Popkin B (1998) Three squares or mostly snacks - what do teens really eat? A sociodemographic study of meal patterns. J Adolesc Health 22, 29-36.

6. Kerver JM, Yang EJ, Obayashi S et al. (2006) Meal and snack patterns are associated with dietary intake of energy and nutrients in US adults. J Am Diet Assoc 106, 46-53.

7. Vereecken C, Dupuy M, Rasmussen M et al. (2009) Breakfast consumption and its socio-demographic and lifestyle correlates in schoolchildren in 41 countries participating in the HBSC study. Int J Public Health 54, Suppl. 2, S180-S190.

8. Utter J, Scragg R, Mhurchu $\mathrm{CN}$ et al. (2007) At-home breakfast consumption among New Zealand children: associations with body mass index and related nutrition behaviors. J Am Diet Assoc 107, 570-576.

9. Dubois L, Girard M, Potvin Kent M et al. (2009) Breakfast skipping is associated with differences in meal patterns, macronutrient intakes and overweight among pre-school children. Public Health Nutr 12, 19-28.

10. Albertson AM, Franko DL, Thompson D et al. (2007) Longitudinal patterns of breakfast eating in black and white adolescent girls. Obesity (Silver Spring) 15, 2282-2292.

11. Barton BA, Eldridge AL, Thompson D et al. (2005) The relationship of breakfast and cereal consumption to nutrient intake and body mass index: the National Heart, Lung, and Blood Institute Growth and Health Study. J Am Diet Assoc 105, 1383-1389.

12. Berkey CS, Rockett HR, Gillman MW et al. (2003) Longitudinal study of skipping breakfast and weight change in adolescents. Int J Obes Relat Metab Disord 27, $1258-1266$.

13. Merten MJ, Williams AL \& Shriver LH (2009) Breakfast consumption in adolescence and young adulthood: parental presence, community context, and obesity. J Am Diet Assoc 109, 1384-1391.

14. Niemeier HM, Raynor HA, Lloyd-Richardson EE et al. (2006) Fast food consumption and breakfast skipping: predictors of weight gain from adolescence to adulthood in a nationally representative sample. J Adolesc Health 39, 842-849.

15. Timlin MT, Pereira MA, Story M et al. (2008) Breakfast eating and weight change in a 5 -year prospective analysis of adolescents: Project EAT (Eating Among Teens). Pediatrics 121, e638-e645.

16. Melnik TA, Rhoades SJ, Wales KR et al. (1998) Overweight school children in New York City: prevalence estimates and characteristics. Int J Obes Relat Metab Disord 22, 7-13.

17. Gleason PM \& Dodd AH (2009) School breakfast program but not school lunch program participation is associated with lower body mass index. J Am Diet Assoc 109, Suppl. 2, S118-S128.

18. Wurbach A, Zellner K \& Kromeyer-Hauschild K (2009) Meal patterns among children and adolescents and their associations with weight status and parental characteristics. Public Health Nutr 12, 1115-1121.

19. Veugelers PJ \& Fitzgerald AL (2005) Prevalence of and risk factors for childhood overweight and obesity. CMAJ 173, 607-613. 
20. Wolfe WS, Campbell CC, Frongillo EA Jr et al. (1994) Overweight schoolchildren in New York State: prevalence and characteristics. Am J Public Health 84, 807-813.

21. United States Department of Agriculture (2009) National school lunch program. http://www.fns.usda.gov/cnd/Lunch/

22. Sen B (2006) Frequency of family dinner and adolescent body weight status: evidence from the national longitudinal survey of youth, 1997. Obesity (Silver Spring) 14, 2266-2276.

23. Taveras EM, Rifas-Shiman SL, Berkey CS et al. (2005) Family dinner and adolescent overweight. Obes Res 13, 900-906.

24. Utter J, Scragg R, Schaaf D et al. (2008) Relationships between frequency of family meals, BMI and nutritional aspects of the home food environment among New Zealand adolescents. Int J Behav Nutr Phys Act 5, 50.

25. Fulkerson JA, Kubik MY, Story M et al. (2009) Are there nutritional and other benefits associated with family meals among at-risk youth? J Adolesc Health 45, 389-395.

26. Franko DL, Striegel-Moore RH, Thompson D et al. (2008) The relationship between meal frequency and body mass index in black and white adolescent girls: more is less. Int J Obes (Lond) 32, 23-29.

27. Prochnik Estima Cde C, da Costa RS, Sichieri R et al. (2009) Meal consumption patterns and anthropometric measurements in adolescents from a low socioeconomic neighborhood in the metropolitan area of Rio de Janeiro, Brazil. Appetite 52, 735-739.

28. Ojala K, Välimaa R, Villberg J et al. (2006) Adolescents' meal patterns: who eats regularly on schooldays? Sos Laaketiet Aikak 43, 60-71.

29. Currie C, Samdal O, Boyce W et al. (editors) (2001) Health Behaviours in School-Aged Children: A World Health Organization Cross-National Study. Research Protocol for the 2001/2002 Survey. Edinburgh: Child and Adolescent Health Research Unit, University of Edinburgh.

30. Westerlund L, Ray C \& Roos E (2009) Associations between sleeping habits and food consumption patterns among 10-11-year-old children in Finland. Br J Nutr 102, 1531-1537.

31. Cole TJ, Bellizzi MC, Flegal KM et al. (2000) Establishing a standard definition for child overweight and obesity worldwide: international survey. BMJ 320, 1240-1243.
32. Nicklas TA, Bao W, Webber LS et al. (1993) Breakfast consumption affects adequacy of total daily intake in children. I Am Diet Assoc 93, 886-891.

33. Singh R, Martin BR, Hickey Y et al. (2009) Comparison of self-reported, measured, metabolizable energy intake with total energy expenditure in overweight teens. Am J Clin Nutr 89, 1744-1750.

34. Lanctot JQ, Klesges RC, Stockton MB et al. (2008) Prevalence and characteristics of energy underreporting in AfricanAmerican girls. Obesity (Silver Spring) 16, 1407-1412.

35. Patel SR \& Hu FB (2008) Short sleep duration and weight gain: a systematic review. Obesity (Silver Spring) 16, 643-653.

36. Ray C, Westerlund L \& Roos E (2007) Do sleeping habits associate with meal pattern among 10-11 years old children? Eur J Public Health 17, 143.

37. Chen MY, Wang EK \& Jeng YJ (2006) Adequate sleep among adolescents is positively associated with health status and health-related behaviors. BMC Public Health 6, 59 .

38. Shaw ME (1998) Adolescent breakfast skipping: an Australian study. Adolescence 33, 851-861.

39. Lattimore PJ \& Halford JC (2003) Adolescence and the diet-dieting disparity: healthy food choice or risky health behaviour? BrJ Health Psychol 8, 451-463.

40. Goodman E, Hinden BR \& Khandelwal S (2000) Accuracy of teen and parental reports of obesity and body mass index. Pediatrics 106, 52-58.

41. Sherry B, Jefferds ME \& Grummer-Strawn LM (2007) Accuracy of adolescent self-report of height and weight in assessing overweight status: a literature review. Arch Pediatr Adolesc Med 161, 1154-1161.

42. Livingstone MB \& Robson PJ (2000) Measurement of dietary intake in children. Proc Nutr Soc 59, 279-293.

43. Vereecken CA \& Maes L (2003) A Belgian study on the reliability and relative validity of the Health Behaviour in School-Aged Children food-frequency questionnaire. Public Health Nutr 6, 581-588.

44. Gaina A, Sekine M, Chen X et al. (2004) Validity of child sleep diary questionnaire among junior high school children. J Epidemiol 14, 1-4. 